\title{
REVIEW KLASTER MRO DI INDONESIA DAN STRATEGI PENGEMBANGANNYA
}

\author{
Freddy Franciscus* \\ Program Studi Teknik Penerbangan, Fakultas Teknologi Kedirgantaraan, \\ Universitas Dirgantara Marsekal Suryadarma \\ Komplek Bandara Halim Perdanakusuma, Jakarta 13610, Indonesia \\ *Corresponding Author : freddyf60@rocketmail.com
}

\begin{abstract}
Abstrak - Pasar MRO di Indonesia tumbuh cukup tinggi yaitu sekitar 9,2\% per tahun sampai dengan 2025, nomor 2 (dua) setelah India yang memiliki laju pertumbuhan pasar MRO sekitar $10,0 \%$ per tahun dan di atas China yang laju pertumbuhannya sekitar $8,7 \%$ per tahun. Pada Tahun 2018 pasar MRO Indonesia sekitar 1 Juta US $\$$ dan hanya terserap oleh MRO Indonesia sekitar 30\% saja. Sebagian besar dari $70 \%$ porsi pasar MRO yang tidak terserap adalah klaster engine dan component maintenance. Sementara itu sebagian besar existing MRO Indonesia adalah klaster engine dan component maintenance. Terjadi anomali penyerapan pasar MRO Indonesia. Penyebab anomali tersebut adalah kapabilitas dan kapasitas MRO Indonesia masih kurang, kualitas MRO belum standar Internasional, kuantitas dan kualitas teknisi masih kurang dan rantai nilai pengadaan spare parts pesawat terbang tidak efisien. Strategi jangka pendek-menengah adalah mengembangkan kapabilitas dan kapasitas existing MRO terutama klaster engine dan component maintenance type pesawat B737-800/900, A320-200 dan ATR 42/72. Meningkatkan kualitas MRO. Meningkatkan kualitas \& kuantitas teknisi. Meningkatkan efisiensi rantai nilai pengadaan spare parts pesawat terbang. Strategi jangka Panjang adalah membangun Aerospace Park di Indonesia Barat, Tengah dan Timur.
\end{abstract}

Kata kunci : MRO, klaster, anomali, aerospace park.

\begin{abstract}
The MRO market in Indonesia is growing quite high at around 9.2\% per year up to 2025, number 2 (two) after India which has an MRO market growth rate of around $10.0 \%$ per year and above China with a growth rate of around $8.7 \%$ per year. In 2018 the Indonesian MRO market is around 1 Million US \$ and only absorbed by Indonesian MRO around $30 \%$. Most of the $70 \%$ portion of the markets that are not absorbed are the engine maintenance and component maintenance. Meanwhile, most existing MRO Indonesia is a cluster of engines and component maintenance. There is an absorption anomaly in Indonesia MRO market. The cause of the anomaly are lack of capability and capacity of Indonesia's MRO, the quality of MROs are not international standard, lack of the quantity and quality of technicians and the value chain of aircraft spare parts procurement is inefficient. The short-medium term strategies are to develop the capability and capacity of existing MROs, especially engine and component maintenance B737-800 / 900, A320-200 and ATR 42/72. Improve the quality of MRO. Improve the quality \& quantity of technicians. Increasing the value chain efficiency in the procurement of aircraft spare parts. The long term strategy is to build Aerospace Park in West, Central and East Indonesia.
\end{abstract}

Keywords: $M R O$, cluster, anomaly, aerospace park 


\section{PENDAHULUAN}

Dari Gambar 1.1 terlihat bahwa laju pertumbuhan jumlah fleet / pesawat terbang di Indonesia tumbuh cukup tinggi.

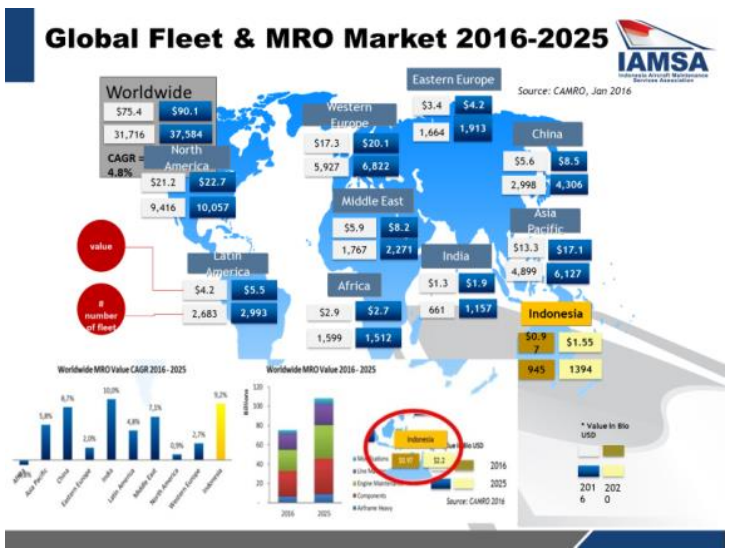

Gambar 1.1 Global Fleet \& MRO Market 2016-2025

Seiring dengan pertumbuhan fleet tersebut terlihat dari Gambar 1.2 bahwa laju pertumbuhan pasar MRO di Indonesia juga cukup tinggi yaitu sekitar 9,2\%/th sampai dengan 2025, nomer 2 (dua) setelah India yang memiliki laju pertumbuhan pasar MRO sekitar 10,0\%/th dan di atas China yang laju pertumbuhannya sekitar $8,7 \% /$ th.

Dari Gambar 1.2 juga terlihat ada lima klaster MRO yaitu Modification, Line Maintenance, Engine Maintenance, Component Maintenance dan Airframe Heavy/Base Maintenance yang masing mempunyai porsi pasar sekitar 1\%, $15 \%$, $35 \%, 40 \%$ dan $9 \%$.

Pertumbuhan pasar MRO di Indonesia tersebut membuka peluang MRO Indonesia untuk menarik sebanyak mungkin pasar perawatan/pemeliharaan pesawat terbang yang dioperasikan oleh maskapai Indonesia.

\section{Global MRO Market 2016-2025}

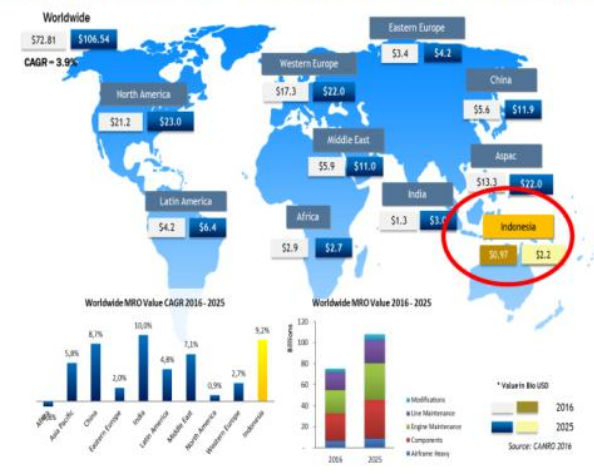

Gambar 1.2 Global MRO Market 20162025

Menurut Ketua IAMSA Ir. Rowin Mangkoesoebroto pada seminar IATEC 13 Maret 2019 di Hotel Mercure Pasar Baru : "Dari peluang pasar MRO di Indonesia sebesar 1 (satu) milyar USD pada tahun 2018, MRO Indonesia hanya bisa mengambil peluang tersebut sebesar 30\% (300 juta USD) sisanya 70\% (700 juta USD) terpaksa diberikan kepada MRO luar negeri". Dari 30\% peluang pasar MRO yang bisa diserap oleh MRO domestik, berdasarkan klaster MRO peluang pasar yang dapat terserap secara keseluruhan adalah klaster Modification (1\%), Line Maintenance (15\%) dan Airframe Heavy / Base Maintenance (9\%), total 25\%. Sementara klaster Engine Maintenance dan Component Maintenance hanya terserap total 5\% yaitu masing-masing $3 \%$ dan $2 \%$. Sisanya yaitu $70 \%$ pasar MRO Indonesia yang terpaksa diserahkan ke MRO luar negeri sebagian besar adalah klaster Engine Maintenance dan Component Maintenance yaitu masing-masing 32\% Engine Maintenance dan 38\% Component Maintenance.

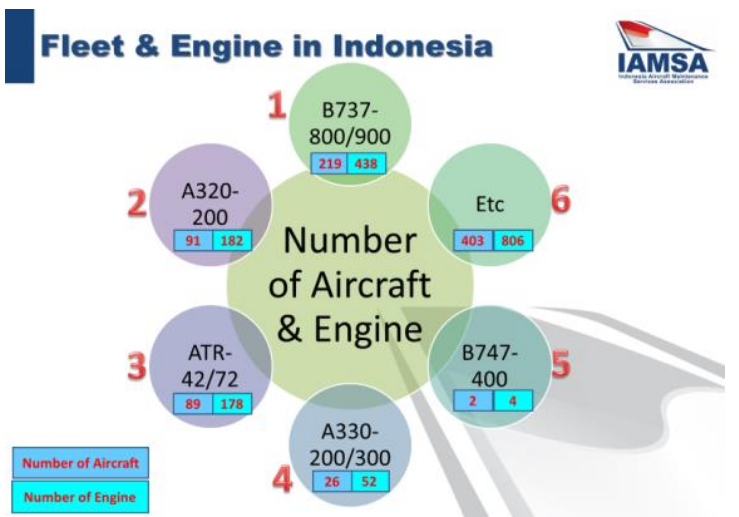

Gambar 1.3 "Fleet \& Engine in Indonesia" 
Dari Gambar 1.3 terlihat bahwa 3 type pesawat terbang yang mempunyai populasi terbanyak di Indonesia adalah B737-800/900, A320-200 dan ATR 42/72. Tentunya secara otomatis populasi engine dari type pesawat tersebut juga mempunyai populasi yang paling banyak.

Banyak lagi type pesawat yang lain di Indonesia, akan tetapi populasi nya jauh lebih kecil dari populasi pesawat B737-800/900, A320-200 dan ATR42/72.

Tabel 1.1 IAMSA Member 2019

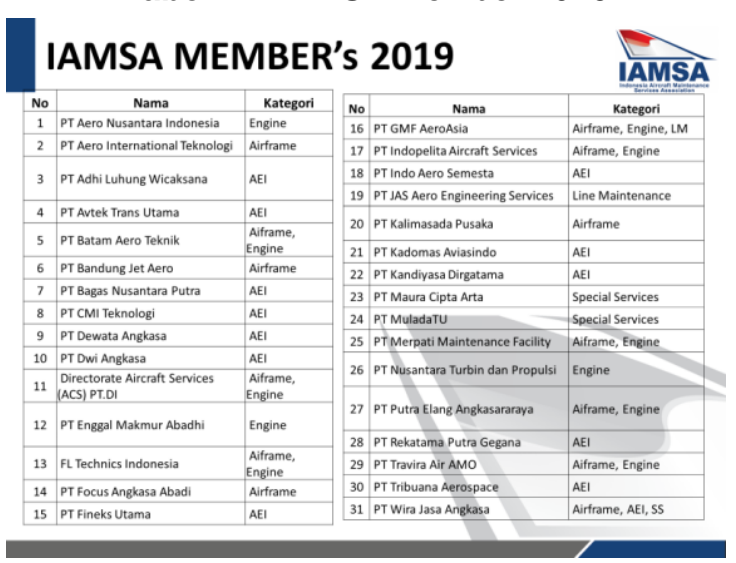

Dari Tabel 1.1 terlihat kapabilitas dari 31 MRO Indonesia anggota IAMSA sesuai klasternya adalah sbb :

1. Capability untuk klaster Modification ada 5 MRO

2. Capability untuk klaster Line Maintenance ada $5 \mathrm{MRO}$

3. Capability untuk klaster Engine Maintenance ada 11 MRO

4. Capability untuk Klaster Component Maintenance ada $21 \mathrm{MRO}$

5. Capability untuk klaster Airframe/Base Maintenance ada 13 MRO

\section{METODE PENELITIAN}

Sebanyak $70 \%$ peluang pasar MRO Indonesia harus diserahkan ke MRO luar negeri, dimana sebagian besar dari $70 \%$ peluang pasar tersebut adalah klaster engine maintenance dan component maintenance. Sementara itu MRO Indonesia sebagian besar mempunyai kapabilitas untuk engine maintenance dan component maintenance.

Hal ini menjadi permasalahan besar yang harus di analisa dan dicari penyebabnya serta dibuat strategi yang mumpuni agar MRO Indonesia bisa menyerap lebih banyak peluang pasar MRO yang ada di Indonesia.

\section{HASIL DAN PEMBAHASAN}

\subsection{Analisa Penyebab Permasalahan}

Beberapa hal yang menjadi penyebab dari permasalahan daya serap pasar MRO Indonesia yang masih rendah, antara lain adalah :

1. Pengembangan kapabilitas dan kapasitas MRO Indonesia belum sesuai dengan kebutuhan dan peluang pasar MRO di Indonesia. Dimana seharusnya yang dikembangkan adalah kapabilitas dan kapasitas MRO klaster component maintenance untuk tipe pesawat B737-800/900, A320-200 dan ATR 42/72 dan juga pengembangan kapabilitas dan kapasitas MRO klaster engine maintenance CFM56-7B untuk tipe pesawat B737-800/900. Kesulitan dalam pengembangan MRO disebabkan antara lain karena untuk membangun kapabilitas dan kapasitas MRO engine maintenance dan component maintenance memerlukan investasi yang cukup besar.

2. Kualitas MRO Indonesia masih belum standar dan masih sedikit yang memiliki sertifikat Internasional (FAA, EASA, AS9110). MRO yang memiliki sertifikat Internasional hanya beberapa, yaitu GMF (FAA, EASA dan AS 9110), BAT (FAA), NTP (FAA dan EASA), Muladatu (FAA) dan JAS Aero Engineering (FAA dan EASA). MRO yang lainnya hanya memiliki sertifikat lokal DGCA. Sulitnya mendapatkan sertifikat Internasional tersebut disebabkan selain karena standar kualitas MRO Indonesia yang masih kurang bagus, juga biaya sertifikasinya cukup mahal dan adanya persyaratan harus merawat pesawat terbang/komponen dari negara yang memberikan sertifikat.

3. Kualitas dan kuantitas teknisi perawatan pesawat terbang dan komponennya masih kurang. 
Kekurangan kualitas dan kuantitas tersebut disebabkan antara lain karena kurang diminatinya sekolah teknisi pesawat terbang yang kalah gengsi dibandingkan dengan sekolah pilot. Selain itu juga karena sekolah teknisi pesawat terbang cukup mahal.

4. Pengadaan barang dan jasa perawatan pesawat terbang dan komponennya di Indonesia masih kurang efisien. Hal tersebut disebabkan karena rantai nilai dari seluruh fungsi yang terkait di dalam bisnis perawatan pesawat terbang masih belum berjalan dengan efektif dan efisien. Masih banyak terjadi inefisiensi dalam rangkaian aktifitas pengadaan, seperti proses pengadaan yang tidak transparan dan pelayanan custom clearance tidak standar.

\subsection{Strategi Pengembangan MRO Indonesia}

Strategi Pengembangan MRO Indonesia agar dapat menyerap lebih banyak peluang pasar MRO Indonesia :

1. Dalam jangka pendek-menengah, mengembangkan existing MRO Indonesia, terutama klaster engine maintenance dan component maintenance untuk tipe pesawat terbang B737-800/900, A320-200 dan ATR 42/72, dengan melakukan hal-hal berikut :

- Mengembangkan kapabilitas dan kapasitas MRO yang ada. Pengembangan kapabilitas dan kapasitas MRO tersebut, karena memerlukan investasi yang cukup besar, sebaiknya dilakukan dengan melakukan kerja sama antar MRO dan Bank dengan melakukan konsorsium.

- Meningkatkan kualitas MRO yang ada agar bisa mendapatkan sertifikat Internasional (FAA/ EASA/AS9110). Karena biaya sertifikasi cukup mahal, maka dapat dilakukan secara bersamasama oleh MRO Indonesia untuk efisiensi biaya dengan 'cost sharing' dan dengan memberdayakan IAMSA/asosiasi perawatan pesawat terbang Indonesia sebagai ujung tombak untuk melakukan koordinasi dan komunikasi authority/konsultan.

- Meningkatkan kualitas dan kuantitas teknisi pesawat terbang MRO Indonesia. Melakukan kerjasama antara MRO dengan Perguruan Tinggi/Politeknik untuk mendapatkan teknisi pesawat terbang yang handal.

- Meningkatkan efisiensi proses pengadaan barang dan jasa spare part pesawat terbang. Melakukan pelayanan satu pintu dengan membangun 'bonded area' agar seluruh fungsi-fungsi terkait dalam proses rantai nilai dapat terintegrasi dan berjalan lancar.

2. Dalam Jangka Panjang, dengan mengembangkan Aerospace Park, yaitu fasilitas perawatan pesawat terbang terpadu/ONE STOP SOLUTION, di lokasi-lokasi berikut :

- Area Barat Indonesia : Bintan

- Area Tengah Indonesia Kertajati/Kulonprogo

- Area Timur Indonesia Makasar/Biak

\section{KESIMPULAN}

Dari peluang pasar MRO Indonesia sebesar 1 Milyar USD pada Tahun 2018, hanya terserap sekitar 30\% (300 Juta USD) dan sekitar 70\% (700 Juta USD) masih di kirim ke MRO luar negeri. Sebagian besar pasar MRO Indonesia yang dikirim ke MRO luar negeri tersebut adalah klaster engine maintenance dan component maintenance. Sementara itu MRO yang ada di Indonesia sebagian besar adalah klaster engine maintenance dan component maintenance. Terjadi kondisi anomali.

Penyebab dari kondisi anomali tersebut adalah karena kurangnya kapabilitas dan kapasitas MRO Indonesia, khususnya klaster engine dan componenet maintenance untuk tipe pesawat terbang yang mempunyai populasi terbanyak yaitu B737-800/900, 
A320-200 dan ATR 42/72. Selain itu juga disebabkan oleh belum standar nya kualitas $\mathrm{MRO}$, masih kurangnya kuantitas dan kualitas teknisi pesawat terbang dan belum efisiennya rantai nilai pengadaan barang dan jasa spare parts pesawat terbang.

Strategi pengembangan MRO Indonesia jangka pendek-menengah adalah mengembangkan kapabilitas dan kapasitas MRO Indonesia terutama klaster engine dan component maintenance terutama tipe pesawat B737800/900, A320-200 dan ATR 42/72. Selain itu juga meningkatkan kualitas MRO, meningkatkan kualitas dan kuantitas teknisi MRO dan meningkatkan efisiens rantai nilai proses pengadaan barang dan jasa. Strategi jangka Panjang membangun aerospace park di lokasi yang mempunyai infrastruktur memadai untuk perawatan pesawat terbang terpadu.

\section{DAFTAR PUSTAKA}

[1] Oliver Wyman, "2015-2025 Global Fleet and MRO Market Forecast" Marsh \& McLennan Companies, Oct 13,2015

[2] IAMSA, "Overcoming The Challenges in Producing more Qualified Aircraft MRO Technicians and Instructors in Indonesia" Seminar IATEC 13 Maret 2019

[3] Indonesia National Air Carriers Association/INACA, "Indonesia Aviation Outlook 2017"

[4] Kementrian Perindustrian RI, "Industri MRO Terintegrasi Dikembangkan" https://kemenperin.go.id, Koran Sindo Oktober 2018

[5] Frost \& Sullivan, "MRO 2025, Identifying Opportunities to Accelerate Growth", 2018
[6] Adrian Schofield, "Indonesia Emerges As One of Asia's MRO Hotspots", Oct 232017

[7] Leithen Francis, "Indonesia Lacks Certified MRO Despite Large, Growing Market" Aviation Week \& Space Technology, Oct 302015

[8] Karen Walker, "Asia-Pacific MRO Market Challenged by Labor Shortage" Aviation Week \& Space Technology, Nov 62015

[9] Darli Rodrigues Vieira \& Paula Lavorato Loures, "Maintenance, Repair and Overhaul (MRO) Fundamentals and Strategies : An Aeronautical Industry Overview", International Journal of Computer Applications (0975-8887), Volume 135-No.12, February 2016. 